\title{
Velocity model influence in the position and geometry of a prospect area located in VSM Basin, by image ray tracing.
}

María Duarte*, Patricia Chajín, Wilman Beltrán, Osmar Díaz, William Agudelo. Ecopetrol S.A.

\section{Copyright 2019, SBGf - Sociedade Brasileira de Geofísica}

This paper was prepared for presentation during the $16^{\text {th }}$ International Congress of the Brazilian Geophysical Society held in Rio de Janeiro, Brazil, 19-22 August 2019.

Contents of this paper were reviewed by the Technical Committee of the $16^{\text {th }}$ International Congress of the Brazilian Geophysical Society and do not necessarily represent any position of the SBGf, its officers or members. Electronic reproduction or storage of any part of this paper for commercial purposes without the written consent of the Brazilian Geophysical Society is prohibited.

\begin{abstract}
Complex structures like subthrust show high risk during the definition of structural traps in time (PSTM) and depth (PSDM) low quality seismic images, so we can use the structural interpretation in time or depth domain to evaluate the velocity model influence in the position and geometry of a prospect area. Ecopetrol acquired a 3D PSTM seismic program in 2011, which has been reprocessed twice in order to improve PSTM image in fault shadow zones and clarify the structural setting to define the closure in a possible trap in the study area to reduce the exploratory risk.
\end{abstract}

In addition, we did an exercise of 2D geophysical modeling using time-depth and depth-time conversion in one inline from the 3D survey. We use time to depth conversion based in image ray tracing, and a structural model interpreted in time (PSTM) and where we test three different velocity field scenarios to do a sensitivity analysis in the velocity model. Then, for depth to time conversion by image ray, we used two different structural models and with velocities derived from RTM seismic processing. Image ray establish a link between time and depth and allows a quick evaluation of structural geometry and pull-up effect presence simultaneously in both domains.

\section{Introduction}

This work presents a 2D geophysical modelling by image ray which located in Magdalena Upper Valley Basin VSM, Colombia, generating five different velocity scenarios (Al-Chalabi, 2014) in a two stages methodology.

First, was simulated image ray (Iversen and Tygel, 2008) in time domain over interpreted structural model (Figure 2 ), and time to depth conversion was done using the velocity scenarios 1, 2 and 3 , getting the same dip direction for the three scenarios. From sensitivity velocity analysis, it was identified that increasing or decreasing the lateral contrast in velocities for the three scenarios, the prospect area does not change and its geometry remains.

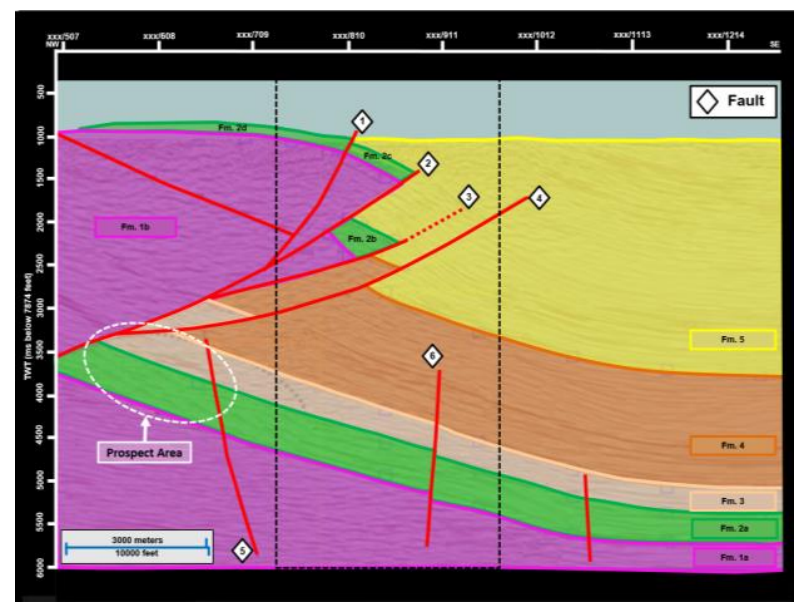

Figure 1 - Interpreted structural model in time domain.

Then, we proposed a depth to time conversion by image ray tracing. The interpreted structural model in depth domain was included RTM seismic processing derived velocities for the 4 and 5 scenarios and converted to time domain each, which showed that geometry of prospect area remains in time and depth domain and the maximum velocity contrast did not generate pull-up effect.

\section{Methodology}

We performed a 2D geophysical modelling in two stages:

Stage 1: The input was a $2 \mathrm{D}$ inline interpreted in time domain from the seismic volume located in the study area (Figure 1) and the P-velocities (Table 1) for each geologic formation were defined using sonic logs and check-shots from 25 wells. The P-velocities were registered in the Table 1.

Then, a geophysical model was generated with three different velocity scenarios in order to compare the extreme velocity scenarios: minimum, average and maximum to simulate greater lateral velocity contrast. In the three velocity scenarios, Formation $1 \mathrm{~b}$ composed of volcano-sedimentary rocks generates greater lateral contrast comparing to the other formations containing mainly sedimentary rocks (Cretacic to Neogene, formations 2, 3, 4 and 5). Figure 2 shows the three velocity scenarios filled with velocities registered in Table 1. 
Table 1 - P-velocities definition for the geologic units of an inline in the study area for scenarios 1,2 and 3.

\begin{tabular}{|c|c|c|c|}
\hline Velocity Scenarios & $\mathbf{1}$ & $\mathbf{2}$ & $\mathbf{3}$ \\
\hline Formation & Minimum (m/s) & Average (m/s) & Maximum (m/s) \\
\hline $1 a$ & 5730 & 5730 & 5730 \\
\hline $1 b$ & 4938 & 5334 & 5730 \\
\hline $2 a$ & 3719 & 3887 & 4054 \\
\hline $2 b$ & 3063 & 3063 & 3063 \\
\hline $2 c, 2 d$ & 3500 & 3500 & 3500 \\
\hline 3 & 3901 & 3947 & 3993 \\
\hline 4 & 3035 & 3451 & 3866 \\
\hline 5 & 2145 & 2479 & 2813 \\
\hline
\end{tabular}

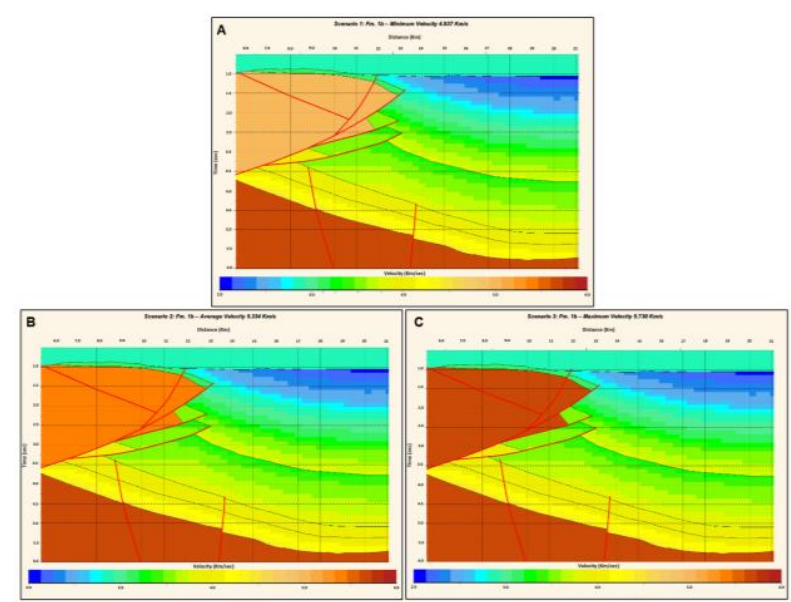

Figure 2 - Geophysical model in time domain: A) Velocities scenario 1 (minimum), Formation $1 \mathrm{~b} 4,937$ $\mathrm{Km} / \mathrm{sec}$. B) Velocities scenario 2 (average), Formation $1 \mathrm{~b}$ $5,334 \mathrm{Km} / \mathrm{sec}$. C) Velocities scenario 3 (maximum), Formation $1 \mathrm{~b} 5,730 \mathrm{Km} / \mathrm{sec}$.

Stage 2: Depth to time conversion, to evaluate the pull-up effect: The position and geometry of the prospect area in time domain were evaluated, to analyze the seismic image low quality in the shadow zone beneath the faults 1, 2, 3 and 4 (Trinchero, 2000), showed inside a black rectangle in the figures 3 and 4 . The inline was interpreted in depth domain generating two scenarios: the first with low dip faults similar to the interpreted faults in time domain (Figure 3); and the second, where the faults were interpreted with high dips, almost vertical dips (Figure 4).

Both scenarios were analyzed with P-velocities from RTM seismic processing volume (Figure 5) and built the geophysical models in depth domain named velocity scenarios 4 and 5 (Figure 6 ) then converted to time domain by image ray.

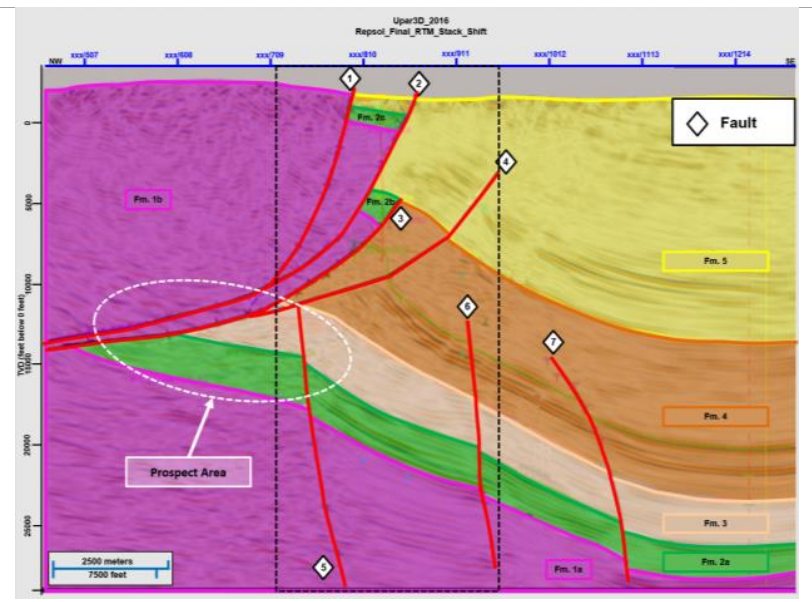

Figure 3 - Interpreted structural model in depth domain with low dip faults.

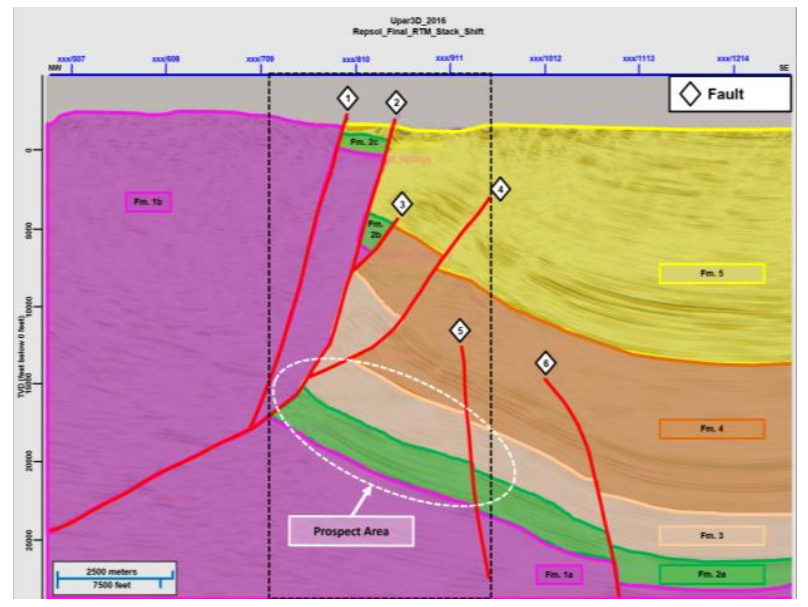

Figure 4 - Interpreted structural model in depth domain with high dip faults.

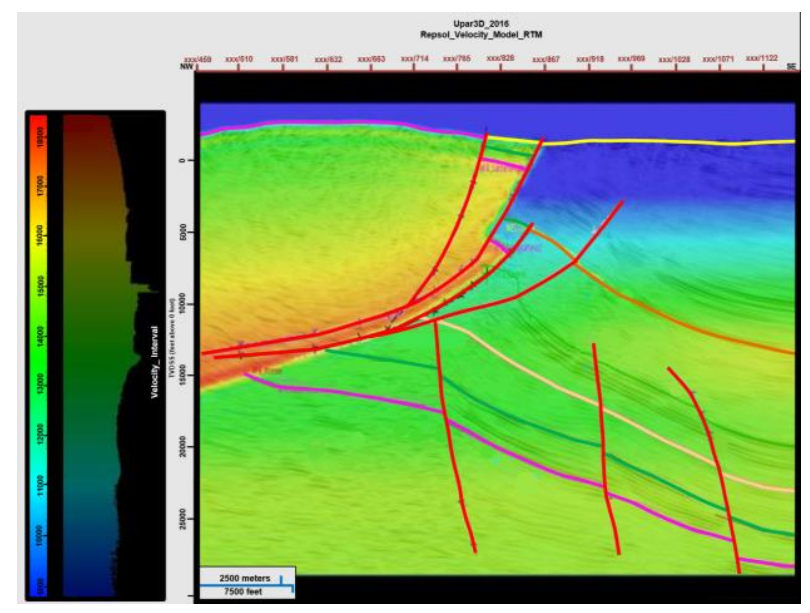

Figure 5 - Velocities model derived from RTM seismic processing volume. 

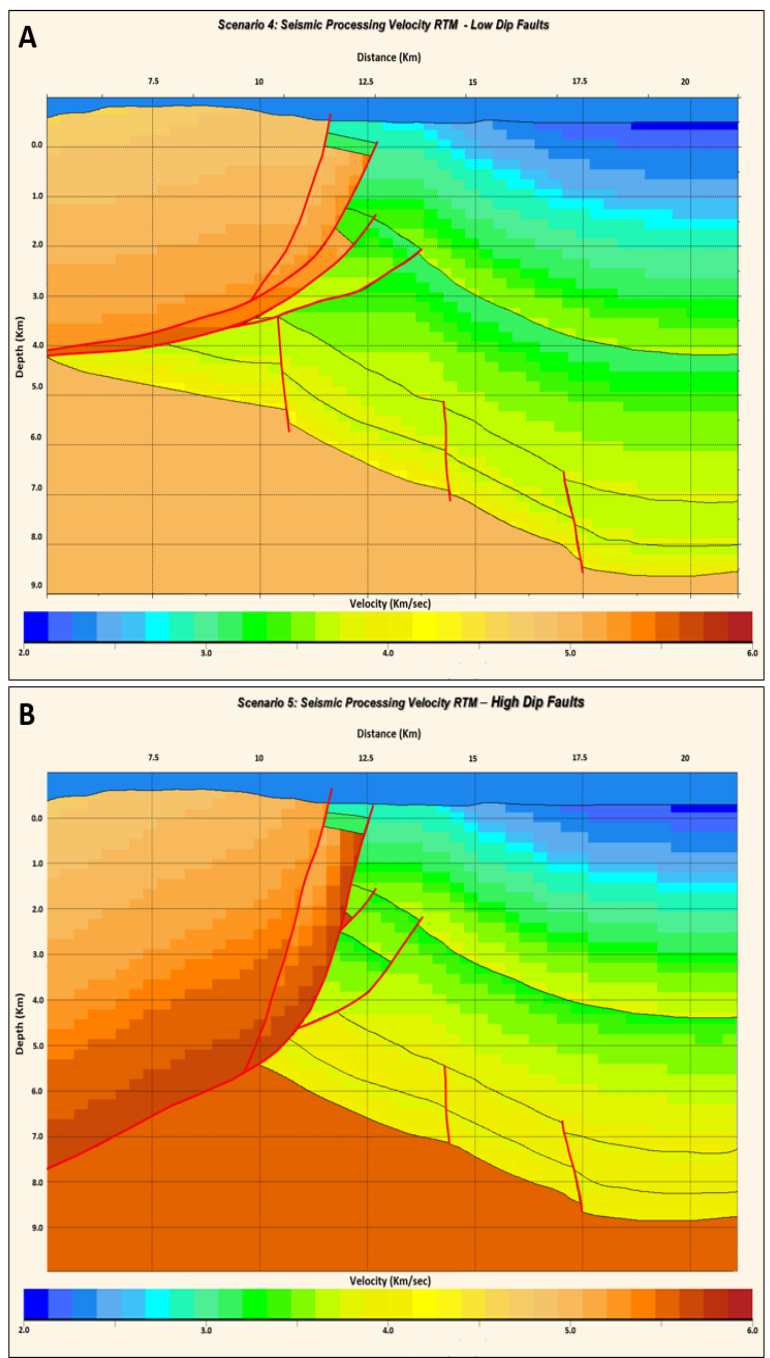

Figure 6 - Velocities model derived from RTM seismic processing volume.

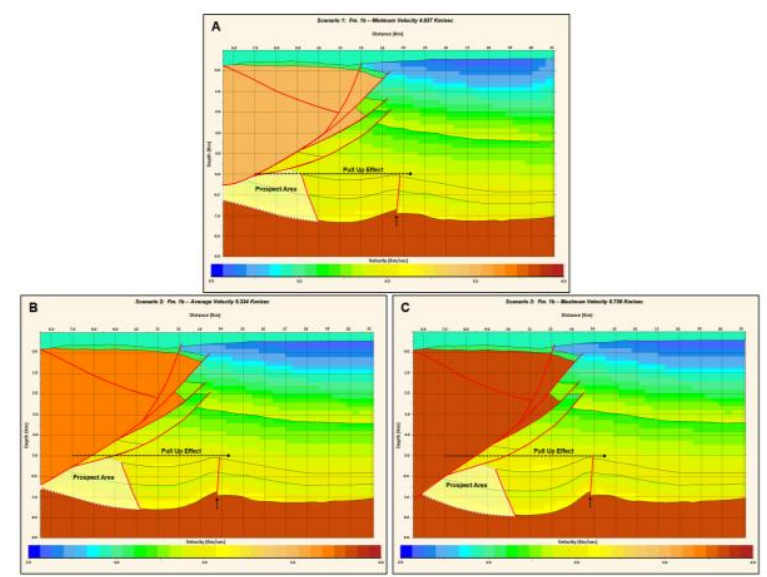

Figure 7 - Geophysical model in depth domain: A) Velocities scenario 1 (minimum). B) Velocities scenario 2 (average). C) Velocities scenario 3 (maximum).

\section{Results}

Figure 7 represents the geophysical model converted from time to depth by image ray tracing, where identified for scenarios 1,2 and 3, a variation in the prospect area position in depth. The variation is between $5 \mathrm{Km}$ and 8 $\mathrm{Km}$ depth, showing in the scenario 3 that Formation $1 \mathrm{~b}$ has the maximum velocity and the prospect area was positioned in a greater depth related with scenarios 1 and 2.

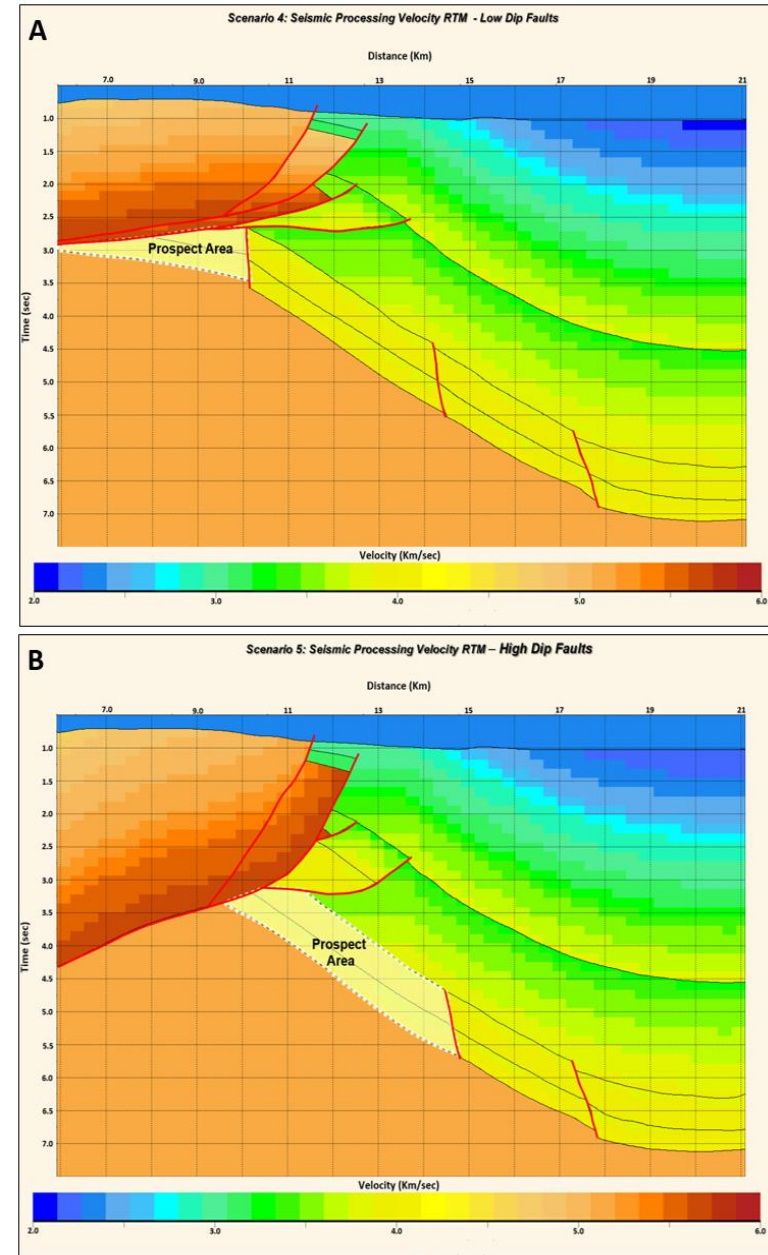

Figure 8 - Geophysical model in time domain: A) Velocities scenario 4. B) Velocities scenario 5.

In the shadow zone beneath the faults 1, 2, 3 and 4 (black discontinuous rectangle, Figure 1), the velocity contrast between hanging wall and footwall cause a pull-up effect. The pull-up effect shows a syncline in the middle of 5 and 6 faults (black discontinuous line, Figure 7) and shows an anticline over the 6 fault (black arrow, Figure 7); being greater in the scenarios filled with a larger velocity range, thus: Scenario 3 has greater pull-up effect that scenario 2 , and scenario 2 has greater pull-up effect that scenario 1.

Figure 7 for the three scenarios (depth domain), the lateral velocity contrast between Formation $1 \mathrm{~b}$ rocks and formations $2 \mathrm{~b}, 2 \mathrm{c}, 4$ and 5 rocks did not affect the 
prospect area and the structural characteristics for a possible trap were better remained in the scenario 3.

In Figure 8, depth to time conversion, in velocity scenarios 4 and 5 , did not show pull-up effect, while dip faults were shown smoother in the time domain, the prospect area position and size varying, on the other hand, the horizons geometry remain its dip to the SE, preserving the structural characteristics for a possible trap.

\section{Conclusions}

This work helps interpreters to evaluate velocity models in time and depth and improves the interpretation process, in particular for zones where image quality is low, like fault shadow zones.

In all tested velocity scenarios (scenarios 1 - 5), was observed that the position of the prospective area varies related to depth and horizontal distance (figures 7 and 8), the geometry of a possible trap remains with the same dip direction to the SE, both in the time domain (scenarios 1 , 2 and 3 ) and in the depth domain (scenarios 4 and 5). However, in depth domain (time to depth conversion) the prospect area is shallower when the lateral velocity contrast is lower (scenario 1) and is deeper when the lateral velocity contrast is greater (scenario 3 ).

Based on time to depth conversion by image ray tracing, was observed that increase and decrease in the lateral velocity contrast in scenarios 1,2 and 3 , causes pull-up effect in the zone located between the faults 5 and 6 matching with the shadow zone beneath the faults $1,2,3$ and 4. The same zone has the highest sensitivity for seismic image artifacts appeared and the worst seismic image (PSTM).

Depth to time conversion by the image ray method was evidenced for scenarios 4 and 5 that: (1) the prospect area geometry is remained in both domains; depth and time. (2) RTM seismic processing velocities used to fill both scenarios, showed the greater lateral velocity contrast between Formation $1 \mathrm{~b}$ and formations 2b, 2c, 4 and 5 , but pull-up effect did not appear in the zone located between faults 5 and $6,(3)$ dip angles of faults 1 , 2, 3 and 4, in the target area were smoothed in the time domain that changes the closure and volume of the possible trap.

Pull-up effect decreases in scenario 1, that correspond to lowest velocities applied in Formation $1 \mathrm{~b}$ (hanging wall from Fault 1) that suggest it should test a new scenario where Formation $1 \mathrm{~b}$ shows better velocity adjustment to match with the study zone geology including non-seismic geophysics methods to build and complement a exclusive velocity profile for this geologic formation.

\section{Acknowledgments}

The authors thank Ecopetrol S.A. for allow to publish this work, especially to the Exploration Vicepresidency - VEX for providing the data and to the Center for Innovation and Technology - ICP for the methodology applied for the achievement of the results.

\section{References}

Al-Chalabi, M. Principles of seismic velocities and time to depth conversion. 2014 EAGE Publications bv. 49 - 91 p.

Duarte, M.T, et. al. Pull-up risk assessment in a workflow combining Time to Depth Image Ray Conversion and PSDM: A case of study at the Catatumbo Basin (Colombia), 2015. Congreso colombiano de geología.

Iversen, E. and Tygel, M. Image ray tracing for joint 3D seismic velocity estimation and time-to-depth conversion, Geophysics, vol. 73, No 3, S99-S114

Trinchero, E., 2000. The fault shadow problem as an interpretation pitfall: The Leading Edge, 19. 